\title{
Fibrin breakdown products and fibrinolysis in renal disease
}

\author{
E. N. WARDLE ${ }^{1}$ AND G. TAYLOR \\ From the Departments of Clinical Haematology and Microbiology, Manchester Royal Infirmary
}

SYNOPSIS In chronic renal failure and after acute renal failure, fibrinogen levels are raised and there is diminished fibrinolysis as the result of renal damage. A similar situation is found in nephrosis, possibly due to fibrinolytic inhibitors.

Increased levels of cryofibrinogen were found in one quarter of cases of acute nephritis, nephrosis, and acute and chronic renal failure. In addition, after acute renal failure low platelet counts, prolonged thrombin times, and high levels of fibrin degradation products, yet with diminished fibrinolysis, indicate that intravascular coagulation has occurred. A positive result for fibrin degradation products was found in 17 of 20 cases of acute renal failure but in none of 10 cases of chronic uraemia.

Intravascular coagulation is a process in which fibrin is deposited in the glomerular filters and may account for anuria, and, in the renal vasculature, where it may cause ischaemic tubular necrosis.

Degradation products of fibrinogen and of fibrin are found in the sera of patients either with the defibrination syndrome or with excessive fibrinolysis. Excessive fibrinolysis may in certain states be a primary phenomenon but perhaps more commonly is a secondary reaction to the intravascular deposition of fibrin. Breakdown products may be detected by several immunological methods (Merskey, Kleiner, and Johnson, 1966).

The precise mechanism of acute renal failure is unknown: it is accepted that such patients have suffered renal ischaemia (Robson, 1966). The important defect appears to be glomerular (Graber and Sevitt, 1959) as there is often little functional evidence of tubular damage. The average renal blood flow may be one-third of normal and yet the glomerular filtration rate only $1 \%$ of normal. It is probably no mere coincidence that the list of causes of acute renal failure (Hardaway, 1966; McKay, 1965 ) is almost the same as the clinical causes of defibrination. The renal glomerulus is designed for filtration and it would not be surprising if unusually viscous material such as fibrin were to block the filters. Indeed, fibrin has now been demonstrated in the renal glomeruli by immunofluorescence in acute renal failure (Koffler and Paronetto, 1966) as well as in toxaemia of pregnancy (Vassalli, Morris, and McCluskey, 1965) and in acute glomerulonephritis and lupus nephritis (Vassalli and

${ }^{1}$ Now at Royal Victoria Infirmary, Newcastle upon Tyne 1. Received for publication 8 June 1967.
McCluskey, 1965). If fibrin breakdown products can be demonstrated in the circulation at the time of or shortly after the development of acute renal failure, then this is some indication that defibrination may be involved in the genesis of that condition. Better still would be the demonstration of the classical parameters of defibrination-hypofibrinogenaemia, thrombocytopenia, prolonged thrombin and silicone clotting times-as has been achieved in acute renal failure of obstetric origin (British Medical Journal editorial, 1965). Unfortunately acute renal failure from other causes so often develops when the patient is at home or under circumstances in which all thought is directed to the associated shock. By the time that investigations are initiated the situation is complicated by the effect of renal damage on the bleeding and coagulation mechanism. Established uraemia may impair platelet function (Castaldi, Rozenberg, and Stewart, 1966) but it is not often the cause of $\sigma$ thrombocytopenia. Fibrinolysis is impaired in $N$ chronic renal disease and fibrinogen levels are $\mathcal{N}$ raised accordingly (Edward, Young, and Macleod, $\omega$ 1964; McNichol, Barakat, and Douglas, 1965). In nephrosis the accompanying lipaemia has an antiplasmin effect and the $\alpha_{2}$ globulin fraction which is elevated has also antifibrinolytic activity. Reduced fibrinolysis and raised fibrinogen levels appear whenever there is renal damage as the kidney is the $\mathbb{D}$ organ which produces plasminogen activator (Proko- $\frac{\Omega}{\square}$ powicz, Warowski, Poplawski, Gabryelewicz, and 을 Niewiarowski, 1967). When there is diminished 
fibrinolysis the demonstration of breakdown products of fibrin would lead to the suspicion that intravascular coagulation had occurred.

This study is in two parts. The first confirms that in chronic renal failure, but also in the nephrotic syndrome and after acute renal failure has occurred, fibrinogen levels may be raised and there is diminished fibrinolysis. The second part of the study demonstrates the presence of fibrin degradation products in the circulation of people with renal and other diseases. In the case of acute renal failure there is corroborative evidence that the fibrin degradation products reflect intravascular coagulation which may in fact be the cause of the acute renal failure.

\section{METHODS}

Specimens of clotted blood (the serum being separated immediately and deep frozen before immunoelectrophoresis), blood in oxalate (for plasma fibrinogen), blood in citrate (for plasminogen), and blood in heparin (for cryofibrinogen) were taken from the patients.

PLASMA FIBRINOGEN This was estimated by dissolving the clot, formed on the addition of thrombin, in boiling sodium hydroxide and measuring the colour developed with Folin-Ciocalteau phenol reagent by absorption at $680 \mathrm{~m} \mu$. A solution of tyrosine was kept as standard (Quick, 1951). Normal values were $130-410 \mathrm{mg}$ per 100 ml.

CRYOFIBRINOGEN (HEPARIN) The precipitate obtained after standing $1 \mathrm{ml}$ heparinized plasma at $4^{\circ} \mathrm{C}$ for 48 hours was washed in cold saline and then dissolved in sodium hydroxide and the blue colour developed with Folin-Ciocalteau reagent. Normal values were less than $120 \mathrm{mg} \%$.

PLASMINOGEN ASSAY Plasminogen in citrated plasma was assayed as plasmin, formed in the presence of optimal amounts of streptokinase, by a caseinolytic technique (Alkjaersig, Fletcher, and Sherry, 1949). Normal values for plasminogen were $1 \cdot 2$ to $2 \cdot 2$ casein units (Sgouris) per ml, derived from a standard curve drawn using plasminogen $\mathrm{B}(\mathrm{Kabi})$ in the test system.

EUGLOBULIN LYSIS TIME This was estimated by the method of Buckell (1958). Normal times were 120-200 minutes.

THROMBIN CLOTTING TIME This was determined on citrated plasma by the method of Hardisty and Ingram (1965).

PLATELETS Counts were made directly in a counting chamber. Normal levels were $\mathbf{2 0 0 - 3 5 0 , 0 0 0 ~ p e r ~ c . m m . ~}$

BREAKDOWN PRODUCTS OF FIBRIN IN SERUM These were studied first by immunoelectrophoresis using a rabbit

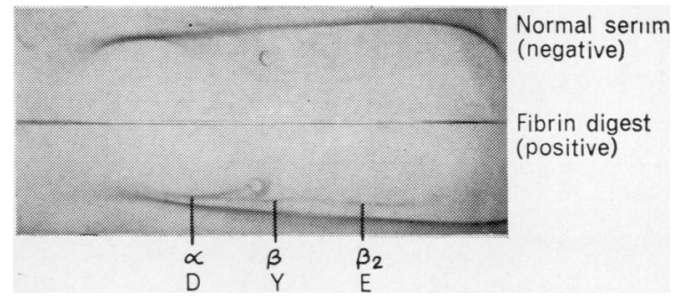

FIG. 1. Immunoelectrophoresis of the anti-split-fibrin serum against the original fibrin digest (positive sample) and against normal serum (negative sample). Split products $D, Y, E$ are identified (Larrieu, Marder, and Inceman, 1966).

antihuman split fibrin serum. The original fibrin digest used to immunize the rabbit was prepared by plasmin digestion of human fibrinogen clotted by the addition of thrombin. The antiserum obtained gave precipitation lines with immunoglobulin $G$ in addition to fibrin breakdown products but it was demonstrated that lines in the $\beta$ region and one in the $a$ region corresponded to major fibrin breakdown products (Fig. 1). In this investigation we have concentrated upon the significance of the fibrin breakdown products seen in the $\beta$ region.

FIBRIN DEgRADATION PRODUCTS These were also assayed quantitatively using the tanned-red cell haemagglutination inhibition technique of Merskey et al. (1966). Doubling dilutions of serum were used up to a titre of $1 / 512$, which, it was estimated, corresponds to 320 micrograms fibrin degradation products per ml. Significant titres were taken to be those over 1:32 corresponding to 20 micrograms fibrin degradation products per $\mathrm{ml}$.

\section{CLINICAL MATERIAL}

Immunoelectrophoresis of serum and the tanned-red-cell test for fibrin breakdown products were performed on sera from various patients admitted to the haematological and renal beds. Seventy-two cases of renal disease, including 20 cases of acute renal failure, were studied in this way and 20 normal persons and 28 patients with various disorders.

Studies on the coagulation and fibrinolytic mechanism were made on over a hundred patients in the same beds. For various reasons it was not always possible to perform the complete series of tests on each individual. All were studied as near as possible to the acute phase of their disease. In the case of acute renal failure the time was usually one to four days after the onset. None had had haemodialysis: some had had peritoneal dialysis.

\section{RESULTS}

Table I summarizes the results for the estimation of plasma fibrinogen, cryofibrinogen (heparin), and for plasminogen. The normal fibrinogen levels were $130-410 \mathrm{mg} \%$ with a mean of $285 \mathrm{mg} \%$. The mean 
TABLE I

SUMMARY OF RESULTS

\begin{tabular}{|c|c|c|c|c|c|c|c|c|c|}
\hline & Fibr & en (mg) & $00 \mathrm{ml})$ & Plas & ggen (ur & $s(m l)$ & Cryc & inogen & $\mathrm{g} / 100 \mathrm{ml})$ \\
\hline & No. & Mean & Range & No. & Mean & Range & No. & Mean & Range \\
\hline $\begin{array}{l}\text { Normal } \\
\text { Nephrotic } \\
\text { Acute renal failure } \\
\text { Acute nephritis } \\
\text { Chronic renal failure }\end{array}$ & $\begin{array}{r}28 \\
28 \\
17 \\
4 \\
16\end{array}$ & $\begin{array}{l}285 \\
390 \\
473 \\
240 \\
470\end{array}$ & $\begin{array}{r}130-410 \\
110-675 \\
90-850 \\
120-410 \\
190-900\end{array}$ & $\begin{array}{r}39 \\
22 \\
16 \\
5 \\
14\end{array}$ & $\begin{array}{l}1 \cdot 7 \\
2 \cdot 0 \\
2 \cdot 06 \\
1 \cdot 77 \\
1 \cdot 82\end{array}$ & $\begin{array}{c}1 \cdot 2-2 \cdot 2 \\
1 \cdot 2-3 \cdot 6 \\
0-3 \cdot 82 \\
1 \cdot 32-2 \cdot 1 \\
0.84-2 \cdot 48\end{array}$ & $\begin{array}{r}26 \\
24 \\
17 \\
5 \\
12\end{array}$ & $\begin{array}{l}71 \\
89 \cdot 5 \\
96 \cdot 5 \\
91 \\
98\end{array}$ & $\begin{array}{r}14-120 \\
15-164 \\
8-200 \\
25-170 \\
8-310\end{array}$ \\
\hline
\end{tabular}

values of the nephrosis, acute and chronic renal failure groups were clearly high. Normal plasminogen values were $1 \cdot 2-2 \cdot 2$ casein units per $\mathrm{ml}$ with a mean value of $1.7 \pm 0.29$ and for the nephrosis group the range was 1.2 to 3.6 with a mean value of $2.0 \pm 0.53$ and the difference is significant $(t=7 \cdot 15$ for $60 \mathrm{df}$ and $\mathrm{P}>0.001$ ). The mean plasminogen value for the acute renal failure group is also high but only just raised in the chronic renal cases group. Comparison of the plasminogen value for the normal cases with the mixed group of acute and chronic renal cases shows that there was greater variation in both values in the cases of renal disease. Cryofibrinogen (heparin) assay gave a normal range of 14 to $120 \mathrm{mg} \%$ with a mean of $71 \pm 29 \cdot 0$, and this too was significantly higher in the nephrosis group for whom the range was $15-164 \mathrm{mg} \%$ with a mean of $89.5 \mathrm{mg} \% \pm 41.0(\mathrm{t}=6.55$ for $48 \mathrm{df}$ and $\mathrm{P}>$ $0.001)$. The cryofibrinogen values were also raised for some of the cases of acute and chronic renal failure and for acute nephritis so that the mean values for these groups are high. If the upper limit of cryofibrinogen is taken at $120 \mathrm{mg} \%$ then seven of 24 cases of nephrosis, seven of 17 cases of acute renal failure, and three of 12 cases of chronic renal failure were found to have raised values at this single estimation. Three of five children with acute nephritis had cryofibrinogen levels in excess of $100 \mathrm{mg} \%$.

Figure 2 deals specifically with the data obtained in the cases of acute renal failure. It shows that at the time of examination, some one to four days after the onset, fibrinogen levels are raised, as also may be cryofibrinogen levels, and about half of the cases have low platelet counts. In five of 13 cases the thrombin times were prolonged. Moreover, at this time fibrinolysis is depressed as shown by prolongation of euglobulin lysis times and normal and slightly elevated plasminogen levels. Only two cases had low plasminogen levels and rapid euglobulin lysis: these were a case of A.P.H. examined at the fourth day and a case of post-prostatectomy anuria examined at the tenth day.

Table II gives the results of immunoelectrophoresis for fibrinogen degradation products in the various clinical categories shown in comparison with the results of the tanned red cell haemagglutination inhibition test. It will be noted that among the 20 normal persons, three gave a positive value. These were women with at the time a high fibrinolytic activity. These cases introduce a note of caution into the interpretation of such results
Fibrinogen

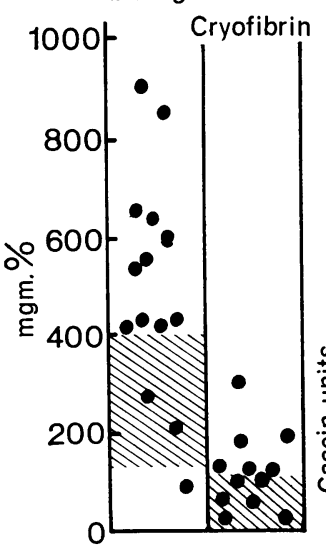

Plasminogen

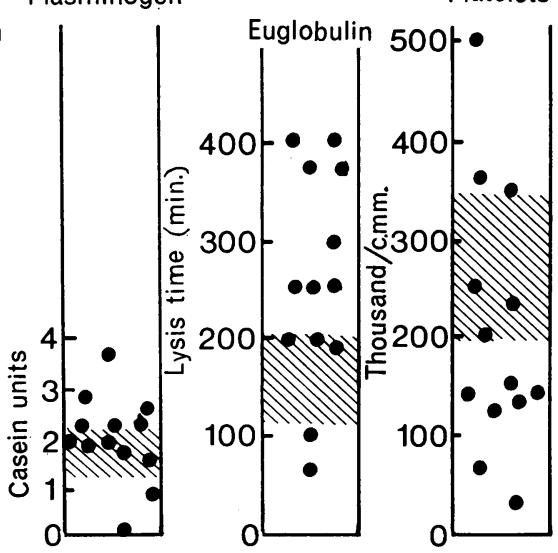

FIG. 2. Data in acute renal failure. Hatched areas indicate normal ranges.

Thrombin time 5 prolonged : 8 normal. 
TABLE II

FIBRIN DEGRADATION PRODUCTS

Immunoelectrophoresis Tanned Red Cell Haemagglutination Inhibition Test

\begin{tabular}{lrrrrr} 
& Positive & Negative & & Positive & Negative \\
\cline { 2 - 3 } \cline { 5 - 6 } Normal & 3 & 17 & & 1 & 9 \\
\hline Cirrhosis & 2 & 1 & & 1 & 2 \\
Venous thrombosis & 2 & 3 & & 2 & 0 \\
Sickle cell anaemia & 1 & 2 & & 0 & 2 \\
PNH & 2 & 1 & & 3 & 2 \\
Purpura & 0 & 5 & & 0 & 4 \\
Ulcerative colitis & 1 & 0 & & 0 & 1 \\
Vasculitis & 0 & 2 & & 1 & 0 \\
Shock & 3 & 1 & & 3 & 1 \\
Acute renal failure & 17 & 3 & & 16 & 4 \\
Chronic renal disease & 0 & 10 & & 5 & 5 \\
Acute nephritis & 2 & 7 & & 3 & 6 \\
Nephrosis & 6 & 20 & & 4 & 20 \\
MHT & 1 & 1 & & 3 \\
Acute pyelitis & 1 & 0 & & 1 & 0 \\
Malignancy (local) & 0 & 3 & 2 & 1 \\
Malignancy & & & & & \\
$\quad$ (disseminated) & 3 & 0 & 3 & 0
\end{tabular}

using a qualitative method, and serve to emphasize that if the fibrionolytic activity is high, then this is an adequate explanation of the fibrin breakdown products but that if the fibrinolytic activity is normal or reduced (all sera were separated and frozen immediately) then the finding of fibrin breakdown products is probably indicative of intravascular coagulation. Moreover, taking a titre of $1.32(20 \mu \mathrm{g}$ fibrin degradation products per $\mathrm{ml}$ ) as significant in the tanned red cell haemagglutination inhibition test one of 10 normal persons gave a positive result.

It will be seen further that positive results were obtained for two of three patients with cirrhosis, who had increased fibrinolytic activity, and for two of five cases of venous thrombosis, one of three cases of sickle cell crisis, and for two of three patients with paroxysmal nocturnal haemoglobinuria who did not have increased fibrinolytic activity. Furthermore, none of 10 cases of chronic uraemia had immunoelectrophoretic circulating fibrin breakdown products but three of four cases of shock and 17 of 20 cases of acute renal failure did. Nevertheless the results can only be interpreted against a knowledge of the history of the patients, of the phase of the illness at which the estimation was performed, and in conjunction with the studies of the coagulation and fibrinolytic mechanism performed at the same time.

Table II shows that there is indeed a fairly good correspondence between the results of immunoelectrophoresis and the tanned red cell haemagglutination inhibition test. The only discrepancy is in the cases of chronic renal failure in which five of 10 cases gave a titre of greater than $1: 32$ in the tanned red cell but were negative on immunoelectrophoresis.

Figure 3 gives a better comparison of the two techniques, showing that there is a fair but not absolute correlation, but emphasizing in particular the high values of fibrin degradation products

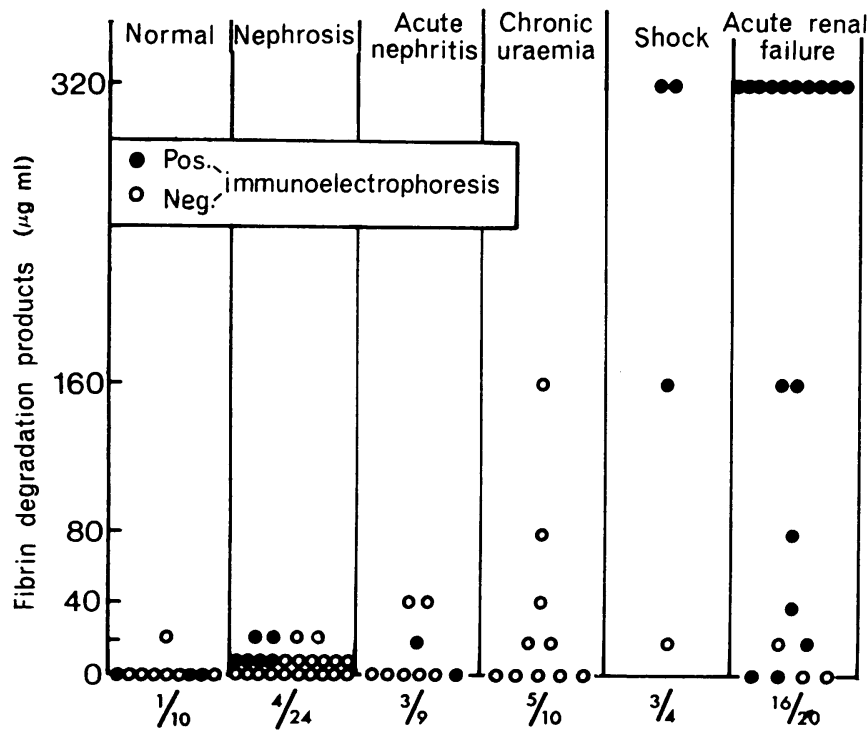

FIG. 3. Tanned red cell haemagglutination inhibition determination of fibrin degradation products and their relationship to clinical condition. $=$ immunoelectrophoresis positive; $\bigcirc=$ immunoelectrophoresis negative.

Proportion of patients having $>20 \mu \mathrm{g} / \mathrm{ml}$. fibrin degradation products 


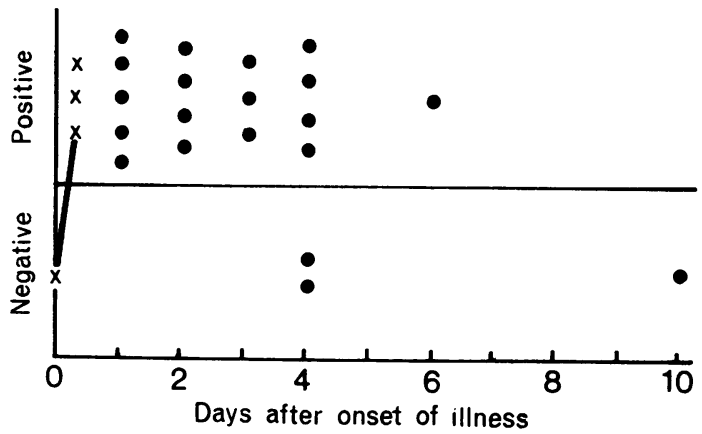

- Acute renal failure $x$ Shock $x-x$ Cardiac arrest

FIG. 4. Detection of circulating fibrin degradation products in relation to time between onset of illness and collection of blood sample.

found in the cases of acute renal failure and also in shock.

Figure 4 shows for the cases of acute renal failure and of shock the time after the onset at which fibrin degradation products were found in the circulation. It will be seen that on average such products were found in the oliguric patient for up to four days after the onset. The cases of shock alone were seen early. Serum taken from a case of cardiac arrest half an hour after the event gave a negative result for fibrin degradation products, but incidentally there was at that time a hypofibrinogenaemia of $90 \mathrm{mg} \%$, and two hours later when the man was still unconscious and shocked fibrin degradation products were present.

Table III gives the aetiology of the types of

TABLE III

AETIOLOGY OF CASES AND IMMUNOELECTROPHORETIC RESULTS

Condition No. of Cases $\frac{\text { Immunoelectrophoresis }}{\text { Nositive No. Negative }}$

Acute renal failure

A.P.H.

Abortion

Dead foetus

Trauma

Postoperative

Acute nephritis rephritis

Acute on chronic

Endotoxin

Pancreatitis

Postoperative

Post partum

Shock

Pancreatitis

Endotoxin

Cardiac arrest

Cardiac arrest acute renal failure and of shock, together with the immunoelectrophoretic results. The case of cardiac arrest has already been commented on. One case of pancreatitis is of interest in that fibrin degradation products were demonstrated in the serum taken two days before the patient actually became oliguric and succumbed to the acute renal failure. Eight of the cases had acute renal failure as an obstetric complication. The group includes also traumatic anuria, acute nephritis, post-cholecystectomy and post-thoracotomy renal failure, and endotoxin shock.

\section{DISCUSSION}

Immunoelectrophoresis for split fibrinogen products cannot determine whether these occur as a result of an intravascular coagulation or as the result of an enhanced fibrinolysis. Thus the positive results obtained by Merskey et al. (1966) included cases both of defibrination and of excessive fibrinolysis. Cases were also found during normal delivery and after myocardial infarction and pulmonary embolism. Ferreira and Murat (1963) used a 'fibrin degradation flocculation test' and found similar positive results in a wide range of conditions, including abruptio placentae, dead foetus syndrome, myocardial infarction, disseminated carcinoma, and during extracorporeal circulation. Merskey et al. estimated that breakdown products at levels up to $768 \mu \mathrm{g} / \mathrm{ml}$ were found in the sera of patients with the defibrination syndrome and up to $576 \mu \mathrm{g} / \mathrm{ml}$ in cases of primary fibrinolysis. Smaller amounts occurred in other disease states and approximately 2.0 to $5.0 \mu \mathrm{g} / \mathrm{ml}$ breakdown products were found in $10 \%$ normal sera.

In the same way as physiological fibrinolysis is linked to physiological intravascular deposition of fibrin, so the pathological state of defibrination certainly engenders an enhanced secondary fibrinolysis (Koller, 1964). Whereas hypofibrinogenaemia with cryofibrinogenaemia, thrombocytopenia, a low prothrombin, and clotting factor depletion indicate defibrination, yet in a pure fibrinolytic state the platelets are normal, the prothrombin is normal, and cryofibrinogen is not found but of course euglobulin lysis is accelerated and plasminogen levels are low. It is very likely that because patients who are victims of a defibrination syndrome can be critically ill, often in shock, with the exception of obstetric cases, they are not investigated at this appropriate early stage and indeed not until fibrinogen levels are restored and there is secondary fibrinolysis. Hardaway has shown in the dog that the liver can restore fibrinogen to the extent of $50 \mathrm{mg} \%$ per hour (Hardaway, 1966). Fibrinogen 
synthesis rates of $20 \mathrm{mg} / \mathrm{kg} /$ day in man can increase at least 20 times.

In the event of shock leading to renal damage with the onset of uraemia, raised fibrinogen levels are found and there is associated reduction of fibrinolysis. Similar findings in chronic renal disease accord with the experience of McNichol et al. (1965) and with that of Edward et al. (1964) and are the direct result of renal damage. However, an important difference noted here is the raised plasminogen levels found in nephrosis, whereas each of the mentioned groups of workers found some low plasminogen values in the nephrotic syndrome. The explanation may lie in the aetiology of the nephrosis, in the form of therapy-steroids or not-or in the degree of azotaemia of the patients. The finding of high plasminogen values in nephrosis is more in accordance with diminished fibrinolytic activity and is probably due in this case to an $\alpha$-globulin inhibitor of plasmin.

Cryofibrinogen does not merely reflect a raised plasma fibrinogen level (McKee, Kalbfleisch, and Bird, 1963), but being the first product in the degradation of fibrinogen (MacFarlane, 1964), it is an indicator of intravascular coagulation (Glueck and Herrmann, 1964), although it is also found when there is extravascular fibrin deposition as in rheumatic fever and rheumatoid disease. The fact that it was found to be raised in various unselected cases of renal disease is of importance. Had all cases been selected in the acute phase, the results might have been even more striking. It should be recalled that McKay and Corey (1964) found cryofibrinogen to be raised in toxaemia of pregnancy, which is thought to be a chronic state of intravascular coagulation (McKay, 1964). In the case of nephrosis it might be postulated that cryofibrinogen is formed because of the action on platelets of circulating antigen-antibody complexes (Robbins and Stetson, 1959), which as Dixon, Feldman, and Vazquez (1961) have shown, can produce in the experimental animal the spectrum of human glomerulonephritis.

Care must be exercised in the interpretation of the results of the immunoelectopboresis. Are these products the result of primary intravascular coagulation or merely of fibrinolysis? As shown here, fibrinolysis is reduced in uraemia, but in individual cases of acute renal failure it can be excessive. Nevertheless, in these cases, with the exception of pancreatitis and the post-prostatectomy state, fibrinolysis is probably secondary to intravascular coagulation. Whichever mechanism is operative, it is clear that in shock or in acute renal failure fibrinogen has been converted to fibrin and to its degradation products.
It has been shown, therefore, that in chronic renal disease and after acute renal failure there is reduced fibrinolysis with prolonged euglobulin lysis times and normal or slightly elevated plasminogen values. The group of patients with acute renal failure show evidence of low platelet counts, impaired thrombin time, raised cryofibrinogen values and the appearance of fibrin degradation products, all of which can be interpreted as corroborative evidence of intravascular coagulation. At this late stage after the onset, raised fibrinogen levels are to be expected. Deposition of fibrin in the renal glomeruli may lead to reduced filtration and be a factor in the production of anuria. Deposition of fibrin in the renal vasculature will, if present for only hours, lead to ischaemic necrosis of tubular cells. In this respect the high fibrinolytic activity of the kidney due to its plasminogen activator content can be seen in a protective role (Januszko, Furman, and Buluk, 1966) (Kwaan, and Fischer, 1965) and will account for the fact that late biopsies show no evidence of fibrin or thrombi.

We are much obliged to Professor D. A. K. Black, Dr. M. C. G. Israels, and Dr. A Holzel for access to cases, and to Dr. G. M. Berlyne for reading the script.

\section{REFERENCES}

Alkjaersig, N., Fletcher, A. P., and Sherry, S. (1949) J. clin. Invest. 38, 1086.

British Medical Journal (1965). Editorial. Defibrination syndrome. 2, 955.

Buckell, M. (1958). J. clin. Path., 11, 403.

Castaldi, P. A., Rozenberg, M. C., and Stewart, J. H. (1966). Lancet, 2,66 .

Dixon, F. J., Feldman, J. D., and Vazquez, J. J. (1961). J. exp. Med., 113, 899.

Edward, N., Young, P. G., and Macleod, N. (1964). J. clin. Path., 17,365 .

Ferreira, H. C., and Murat, L. G. (1963). Brit. J. Haemat., 9, 299.

Glueck, H. I., and Herrmann, L. G. (1964). Arch. intern. Med., 113, 748 .

Graber, I. G., and Sevitt, S. (1959). J. clin. Path., 12, 25.

Hardaway, R. M. (1966). Syndromes of Disseminated Intravascular Coagulation. Thomas, Springfield, Ill.

Hardisty, R. M., and Ingram, G. I. C. (1965). In Bleeding Disorders: Investigation and Management. p. 285. Blackwell, Oxford.

Januszko T., Furman, M., and Buluk, K. (1966). Thrombos. Diathes. haemorrh. (Stuttg.), 15, 554.

Koffler, D., and Paronetto, F. (1966). Amer. J. Path., 48, p. 40 (Abstr).

Koller, F. (1964). Acta haemat. (Basel), 31, p. 4a. (Abstr.).

Kwaan, H. C., and Fischer, S. (1965). Fed. Proc., (Abstr. 1428) 24, 387.

Larrieu, M. J., Marder, V. J., and Inceman, S. (1966). Thrombos. Diathes. haemorrh. (Stuttg.), suppl. 20, p. 215.

MacFarlane, R. G. (1964). The clotting mechanism. In Biochemical Disorders in Human Disease, edited by R. H. S. Thompson and E. J. King p. 203. Churchill, London.

McKay, D. G. (1965). Disseminated Intravascular Coagulation. Harper and Row, New York.

, and Corey, A. E. (1964). Obstet, and Gynec, 23, 508.

(1964). Circulation, 30, suppl. 2, 66.

McKee, P. A., Kalbfleisch, J. M., and Bird, R. M. (1963). J. Lab. clin. Med., 61, 203.

McNichol, G. P., Barakat, A. A., and Douglas, A. J. (1965). Scot. med.J., 10, 189. 
Merskey, C., Kleiner, G. J., and Johnson, A. J. (1966). Blood, 28, 1. Prokopowicz, J., Worowski, K, Poplawski, A., Gabryelewicz, A., and Niewiarowski, S. (1967). Thrombos. Diathes. haemorrh. (Stuttg.), 17, 1.

Quick, A. J. (1951). The Physiology and Pathology of Hemostasis. Kimpton, London.

Robbins, J., and Stetson, C. A. Jr. (1959). J. exp. Med., 109, 1.
Robson, J. S. (1966). In Second Symposium on Advanced Medicine: Proceedings of a Conference at Royal College of Physicians of London, 1965. Edited by J. R. Trounce, pp. 79-95. Pitman, London.

Vassalli, P., and McCluskey, R. T. (1965). Amer. J. Med., 39, 179. -, Morris, R. H., and McCluskey, R. T. (1965). J. exp. Med., 118, 467. 